\title{
IMPLEMENTASI PENDIDIKAN ANTIKORUPSI UNTUK MENINGKATKAN MORALITAS MAHASISWA PPKN UNIVERSITAS SULTAN AGENG TIRTAYASA
}

\section{(Studi Deskriptif Terhadap Moral Knowing dan Moral Feeling)}

\author{
Ade Millatus Sa'adiyyah ${ }^{1}$, Aryanti Dwi Untari ${ }^{2}$, Nibras Shohwatul Islam ${ }^{3}$ \\ ${ }^{123}$ Universitas Banten Jaya \\ Serang, Indonesia
}

$\underline{\text { ade.millatus@gmail.com }}{ }^{1}$, aryantidwiu@gmail.com², Nibrasshohwatul3@gmail.com ${ }^{3}$

\begin{abstract}
The phenomenon of corruption in Indonesia in various aspects of life is not a new thing. Likewise, corrupt behavior has often occurred in everyday life. In fact, ironically, a person sometimes does not know that his actions are corrupt behavior. Corruption is a crime committed either individually or in groups, taking what is not their right with the aim of enriching themselves. Corruption is carried out as a shortcut to enrich oneself without being responsible for the aftermath. The government has taken many ways to make Indonesia free from corruption. However, to realize an Indonesia that is honest and free from acts of corruption is an agenda that requires attention and a very long effort by leaders who are aware of honesty and are free from acts of corruption that are deeply rooted in Indonesian culture. This study aims to: 1) determine the implementation of anti-corruption education in improving the morality of PPKn Untirta students, 2) to find out the learning strategies of anti-corruption education courses in improving the morality of PPKn Untirta students, 3) To find out the forms of morality reflected in PPKn Untirta students. This research is a descriptive research with a qualitative approach. The subjects of this study were the Head of the PPKn Untirta Department, Lecturers of Anti-Corruption Education Courses, and PPKn Students. Data was collected using the methods of observation, interviews, and documentation. Data analysis techniques used are data reduction, data presentation, and drawing conclusions. Test the validity of the data using source triangulation. The results showed that: 1) Implementation of Anti-Corruption Education in Improving the Morale of PPKn Untirta Students, (a) Supporting activities: socialization, seminars, habits. 2) Increasing student morality in implementing anti-corruption values.
\end{abstract}

Keywords: Implementation, Anti-Corruption Education, Student Morale.

\section{PENDAHULUAN}

Pendidikan merupakan suatu proses pembelajaran terhadap manusia secara terus menerus, agar manusia tersebut menjadi pribadi yang amil (sempurna) lahir dan batin Juwono Sudarsono (2008). Menurut Herman Suparno bahwa Kemajuan suatu bangsa sangat ditentukan oleh kualitas pendidikan. Oleh karena itu, pendidikan sebagai sarana untuk mencerdaskan kehidupan bangsa memiliki peranan yang sangat strategis. Pendidikan berkontribusi dalam mengembangkan sumber daya manusia (SDM) yang bermutu, dengan indicator berkualifikasi ahli, terampil, kreatif, inovatif, serta memiliki attitude (sikap dan perilaku) 
yang positif. Amanat Pembukaan UUD 1945 dan visi Pendidikan nasional merujuk pada suatu landasan filsafat yang amat mendalam, yangdalam pasal 31 Ayat 1 UUD 1945 dinyatakan sejalan dengan Hak Asasi Manusia untuk belajar. Ini berarti bahwa secara legal System pendidikan dilandasi oleh suatu filsafat pendidikan yang mendalam yang mengakui perbedaan unik pribadi individu. Artinya, keragaman, martabat, serta peradaban nilai dalam pertumbuhan anak Indonesia secara implisit mengandung peluang untuk mewujudkan asas eksplorasi dan kecenderungan kreatif dalam seluruh tumbuh kembangnya. Hal tersebut telah diulangi dalam Undang-Undang Nomor 20Tahun 2003 tentang Sistem Pendidikan Nasional (Pasal 5). Dalam hal ini salah satu nya mengenai penanaman Pendidikan anti korupsi di lingkungan Perguruan Tinggi.

Upaya pencegahan budaya korupsi di masyarakat terlebih dahulu dapat dilakukan dengan mencegah berkembangnya mental korupsi pada anak bangsa Indonesia melalui pendidikan. Hal ini disadari bahwa memberantas korupsi juga tak lepas dari gerakan preventif, yaitu mencegah timbulnya mental korupsi pada generasi anak bangsa. Mengingat upaya pencegahan tersebut tidak hanya dapat dilakukan pada satu generasi saja, melainkan dua atau tiga generasi selanjutnya. Pendidikan Anti Korupsi bagi mahasiswa bertujuan untuk memberikan pengetahuan yang cukup tentang seluk beluk korupsi dan pemberantasannya serta menanamkan nilai-nilai anti korupsi. Tujuan jangka panjangnya adalah menumbuhkan budaya anti korupsi di kalangan mahasiswa dan mendorong mahasiswa untuk dapat berperan serta aktif dalam upaya pemberantasan korupsi di Indonesia. Fenomena korupsi di Indonesia dalam berbagai kehidupan sudah bukan merupakan hal yang baru. Demikian juga dengan perilaku koruptif, sudah sering terjadi di dalam kehidupan keseharian. Bahkan, ironisnya, seseorang terkadang tidak mengetahui bahwa perbuatan yang dilakukannya termasuk perilaku koruptif. Korupsi merupakan tindakan kejahatan yang dilakukan baik secara individu atau kelompok, mengambil yang bukan haknya dengan tujuan untuk memperkaya diri sendiri. Korupsi dilakukan sebagai jalan pintas untuk memperkaya diri sendiri tanpa perlu bertanggung jawab terhadap dampak setelahya. Nanang, dkk (2011:23) korupsi sesungguhnya sudah lama ada terutama sejak manusia pertama kali mengenal tata 
kelola administrasi. Pada kebanyakan kasus korupsi yang dipublikasikan pemerintahan. Korupsi juga sering dikaitkan pemaknaannya dengan politik. Sekalipun sudah dikategorikan sebagai tindakan yang melanggar hukum, pengertian korupsi dipisahkan dari bentuk Chazawi (2016:1) istilah korupsi berasal dari satu kata dalam bahasa Latin yakni corruption atau corruptus, yang mengandung arti perbuatan korup, penyuapan. Secara harfiah istilah tersebut berarti segala macam perbuatan yang tidak baik, seperti yang dikatakan Andi Hamzah dalam Chazawi (2016:1) sebagai kebusukan, keburukan, kebejatan, ketidakjujuran, dapat disuap, tidak bermoral, penyimpangan dari kesucian, kata-kata atau ucapan yang menghina atau memfitnah. Dalam arti sosial tampaknya masyarakat memang mengasosiasikan korupsi sebagai penggelapan uang (milik negara atau kantor) dan menerima suap dalam hubungannya dengan jabatan atau pekerjaan, walaupun dari sudut hukum tidak persis sama. Mengingat dari sudut hukum banyak syarat/unsur yang harus dipenuhi bagi suatu tingkah laku agar dapat dikualifikasikan sebagai salah satdari tindak pidana korupsi sebagaimana dirumuskan dalam undang pelanggaran hukum lainnya. Selain mengkaitkan korupsi dengan politik, korupsi juga dikaitkan dengan perekonomian, kebijakan publik, kebijakan internasional, kesejahteraan sosial, dan pembanguunan nasional. undang. Indonesia Corruption Watch (2020:21) melakukan pemetaan kasus dugaan korupsi berdasarkan daerah yang rawan terjadi tindak pidana korupsi. Dari 34 provinsi yang dipantau oleh ICW, hanya 32 provinsi yang informasi mengenai penanganan perkara korupsinya. Sedangkan sisanya tidak ditemukan adanya pemberitaan mengenai penanganan perkara korupsi yang masuk dalam tahap penyidikan, yakni Provinsi Daerah Istimewa Yogyakarta dan Provinsi Kalimantan Utara. Hal ini dilakukan sebagai upaya untuk melihat tingkat kerentanan suatu daerah dalam melakukan tindak pidana korupsi. Sebagai catatan, pemetaan terhadap provinsi tidak dapat menjadikan dasar bahwa suatu daerah paling korup. Ada 2 (dua) indikator yang menyebabkan tingginya kasus dugaan korupsi di daerah. Pertama, tingginya partisipasi masyarakat dalam melaporkan kasus dugaan korupsi dan mengawasi 
penanganan perkara korupsi di penegak hukum. Kedua, aktifnya penegak hukum melakukan penindakan kasus korupsi dan informasinya disampaikan ke publik.

Kasus korupsi yang semakin banyak mahasiswa dengan pendidikan. Sejalan dengan pernyataan tersebut Wibowo (2014:36) mengemukakan bahwa: "Pendidikan mampu menjadi upaya preventif bagi berkembangnya sikap, perilaku, dan budaya antikorupsi, meskipun secara empiris jelas tidak cukup mengingat faktor pressure sosial politik yang dapat juga mendistorsi peran normatif tersebut. Kendati demikian, jika ada kemauan keras dari segenap komponen bangsa untuk menjadikan pendidikan sebagai panglima melawan korupsi, jelas bukan hal mustahil untuk direalisasikan." Pendidikan tidak lepas dari proses kehidupan manusia. Melalui pendidikan manusia mengetahui bagaimana hakikat mereka bisa hidup dan bisa berinteraksi secara sosial. Oleh karena itu selama ada kehidupan, selama itu manusia akan selalu ada di dunia. Salah satu bentuk penyelesaian masalah manusia yakni dengan pendidikan. Pendidikan saat

Hakim (2012:141) pada dasarnya pendidikan anti korupsi dapat diartikan sebagai salah satu program pendidikan yang menjelaskan dan menanggulangi berbagai korupsi yang terjadi di kalangan masyarakat menjerat para pelakunya, maka perlu mengambil langkah berupa tindakan pencegahan terhadap generasi penerus bangsa yang salah satunya adalah

ini tentu menjadi kunci dari berbagai masalah yang dialami bangsa Indonesia saat ini. Ketika manusia mampu memahami dimensi pendidikan yang sebenarnya maka manusia tersebut akan bisa memanfaatkan setiap waktu di dalam kehidupannya. Berbagai masalah yang terjadi di Indonesia saat ini tentu membutuhkan penyelesaian yang cepat dan konkret. Tentu hal ini dapat dilakukan melaluipendidikan. Permasalahan korupsi tentu menjadi objek kajian yang menarik untuk dikaji secara umum. Upaya pencegahan pendidikan antikorupsi harus dilakukan pada perguruan tinggi melalui matakuliah wajib/pilihan yang relevan di kalangan mahasiswa, untuk mewujudkan aksi pengembangan tersebut untuk itu perlu melakukan penelitian untuk mengetahui bagaimana implementasi nilainilai pendidikan antikorupsi yang telah melekat dalam diri mahasiswa

dengan upaya penanaman sedini mungkin jiwa antikorupsi dengan tujuan untuk membangun dan meningkatkan kepedulian warga negara terhadap bahaya dan akibat dari tindakan korupsi. Pendidikan 
antikorupsi memiliki tiga tujuan, pertama, membentuk pengetahuan dan pemahaman bentuk korupsi dan aspek-aspeknya. Kedua, mengubah persepsi dan sikap terhadap korupsi. Ketiga, membentuk keterampilan dan kecakapan baru yang ditujukan untuk melawan korupsi. Berdasarkan uraian diatas maka peneliti tertarik untuk melakukan

\section{METODE PENELITIAN}

Penelitian ini menggunakan pendekatan kualitatif, karena secara langsung dapat menyajikan hubungan antara peneliti dan responden lebih peka. Menurut Bog dan Tylor dalam Moloeng (2014:4). metode kualitatif adalah "prosedur penelitian yang menghasilkan data dekskriptif, yang berupa kata-kata tertulis atau lisan dari orang-orang dan perilaku yang diamati”. Data yang dikumpulkan oleh peneliti bukan berupa angka-angka, melainkan data tersebut berasal dari naskah wawancara, catatan lapangan, dokumen pribadi, dan dokumen resmi lainnya dan dideskripsikan dalam bentuk narasi. Prosedur pengumpulan data dalam penelitian ini menggunakan beberapa metode agar diperoleh data yang lengkap. Metode yang digunakan untuk mengumpulkan dalam penelitian ini adalah observasi, wawancara, dan penelitian dengan judul

“ Implementasi Pendidikan Anti Korupsi Untuk meningkatkan Moralitas Mahasiswa PPKN UNiversitas Sultan Ageng Tirtayasa “ (Studi Deskriptif Terhadap Moral Knowing dan Moral Feeling).

dokumentasi. Pada penelitian ini, teknik analisis data yang digunakan peneliti menggunakan model Miles dan Huberman. Miles dan Huberman (1984) dalam Sugiyono (2017: 246). Aktivitas analisis data, yaitu data reduction, data display, dan conclusion drawing/verification. Rencana pengujian keabsahan data dalam penelitian ini, menggunakan kredibilitas, transferability, dependability, konfirmability. Dalam penelitian, menggunakan pendekatan kualitatif dengan menggunakan metode deskriptif, karena peneliti bermaksud untuk mengetahui tentang Implementasi Pendidikan Antikorupsi untuk Meningkatkan Moralitas Mahasiswa PPKn Universitas Sultan Ageng Tirtayasa. 


\section{PEMBAHASAN}

Berdasarkan hasil penelitian yang peneliti peroleh bahwasannnya Jurusan PPKn (MKWU) di Jurusan PPKn. Universitas Sultan Ageng Tirtayasa sebagai kampus yang memiliki visi Terwujudnya Untirta Sebagai Integrated Smart and Green (It's Green) University yang Unggul, Berkarakter dan Berdaya Saing, di Kawasan ASEAN tahun 2030 turut menerapkan Pendidikan Antikorupsi. Latar belakang kampus ini menjalankan kebijakan tersebut adalah dikarenakan permasalahan korupsi di Indonesia yang tak kunjung usai, serta adanya optimalisasi dalam menjalankan tata kelola pemerintahan yang baik, bersih, efektif dan berintegritas itu diawali dengan upaya preventif yang dilakukan sejak dini, dan hari ini mendidik mahasiswa untuk menjadi pemimpin yang bersih dari korupsi adalah sasaran yang tepat dalam mengedukasi bahaya korupsi. Untirta juga melakukan upaya sinkronisasi dan kolaborasi dengan salah satu lembaga yang mempunyai peran aktif dalam menjaga integritas nilai-nilai antikorupsi dan mengadvokasi kasuskasus korupsi yang terjadi dan berkembang. Selain itu, faktor penunjang pembelajaran lainnya seperti halnya sarana dan prasarana kampus mencoba disesuaikan dengan kebutuhan proses pembelajaran
Untirta telah menerapkan kurikulum Pendidikan Antikorupsi sebagai Mata Kuliah Wajib Umum

mata kuliah antikorupsi agar dapat berjalan secara optimal, bahkan tidak hanya support dari unsur infrastruktur saja, melainkan untuk terus menghegemoni SDM agar lebih kritis dalam menangkal isu dan kasus korupsi Jurusan PPKn Untirta dan keterlibatan dosen dalam menggelar kegiatan-kegiatan yang memfokuskan untuk meningkatkan SDM unggul dan sangat partisipatif.

Implementasi

Pendidikan

Antikorupsi Untuk Meningkatkan

Moralitas Mahasiswa PPKn

Universitas Sultan Ageng Tirtayasa

Implementasi Pendidikan Antikorupsi Untuk Meningkatkan Moralitas Mahasiswa PPKn Universitas Sultan Ageng Tirtayasa berawal dari adanya Peraturan Menteri Riset, Teknologi dan Pendidikan Tinggi (Permenristekdikti) No. 33 Tahun 2019 tentang Penyelenggaraan Pendidikan Antikorupsi di Perguruan Tinggi, KPK bersama mitra pemangku kepentingan juga melakukan inovasi dan pengembangan bahan pembelajaran lain berupa komik, buku saku, film, dan papan permainan (boardgame) sehingga media ajar pembelajaran antikorupsi jadi 
lebih menarik dan variatif.

\section{Strategi Pembelajaran Mata Kuliah \\ Pendidikan Antikorupsi Untuk \\ Meningkatkan Moralitas Mahasiswa \\ PPKn Universitas Sultan Ageng}

\section{Tirtayasa}

Strategi pembelajaran dapat diartikan setiap kegiatan yang dipilih, yang dapat memberikan fasilitas atau bantuan kepada mahasiswa dalam menuju tercapainya tujuan pembelajaran tertentu. Oleh karena itu, strategi implementasi pendidikan antikorupsi dapat melalui penerapan strategi pembelajaran dengan cara mengintegrasikan nilai-nilai antikorupsi ke dalam pembelajaran. Strategi untuk melakasanakan proses pembelajaran secara efektif dan efisien adalah dengan upaya untuk melakukan pendekatan persuasif agar mampu merasakan pembelajaran secara nyata. Penanaman nilai-nilai antikorupsi yang disampaikan secara terintegrasi, dosen dapat memilih nilainilai yang akan ditanamkan melalui materi bahasan pada Pendidikan Antikorupsi. Hal ini sejalan dengan Agus Wibowo (2013: 57) bahwa pengembangan pendidikan antikorupsi terintegrasi ke dalam mata Pertama, strategi untuk menanamkan nilai kejujuran ke diri mahasiswa dalam pelajaran, pengembangan diri, dan budaya sekolah. Sehingga nilai-nilai acuan pendidikan antikorupsi harus diintegrasikan ke dalam Rencana Pelaksanaan Pembelajaran. Nilai-nilai antikorupsi yang

diintegrasikan ke dalam mata kuliah memperhatikan beberapa hal sebagai berikut: a) Integrasi dalam Mata Pelajaran yang Sesuai, b) Integrasi dalam Kegiatan Pengembangan Diri, c) Pariatif Model Pembelajaran.

\section{Bentuk-Bentuk Moralitas yang} Tercermin dalam Diri Mahasiswa PPKn Universitas Sultan Ageng Tirtayasa

Dari penelitian yang peneliti peroleh, substansi dari adanya pendidikan antikorupsi ini menitikberatkan pada moralitas nilai-nilai anti korupsi yang diterapkan dalam diri mahasiswa sebagai hasil dari adanya kurikulum pendidikan anti korupsi. Nilai-nilai moralitas anti korupsi ini meliputi kejujuran, kepedulian, kemandirian, kedisiplinan, tanggung jawab. Nilainilai inilah yang akan mendukung prinsip-prinsip anti korupsi untuk dapat dijalankan dengan baik.

implementasi pendidikan anti korupsi di PPKn Untirta, yaitu menekankan kepada 
kepada mahasiswanya agar tidak melakukan nilai-nilai yang bertentangan dengan kejujuran.Kedua, Penanaman nilai kepedulian di Jurusan PPKn Untirta telah ditekankan oleh kampus melalui adanya pembiasaan untuk saling membantu satu sama lain, berbagi untuk yang lebih membutuhkan, membantu ketika ada teman yang sedang mengalami musibah dengan mengumpulkan dana secara sukarela. Selain itu, interaksi antara mahasiswa dengan mahasiswa, mahasiswa dengan dosen, dan sebaliknya berjalan dengan sangat baik. Hal ini dikarenakan Kampus Untirta memiliki budaya $5 \mathrm{~S}$, yaitu Senyum, Sapa, Salam, Sopan, Santun. Sehingga, dapat dilihat bahwa warga kampus masih memiliki kepedulian untuk melaksanakan budaya $5 \mathrm{~S}$ tersebut. Ketiga, nilai kemandirian dapat diwujudkan antara lain dalam bentuk mengerjakan tugas secara mandiri dan mengerjakan ujian secara mandiri sesuai dengan tanggung jawabnya sebagai seorang mahasiswa. Selain itu, nilai kemandirian dapat juga diwujudkan melalui kemampuannya dalam berarti mahasiswa mempunyai tanggung jawab untuk memimpin Himpunan dengan baik. Ataupun jika terpilih menjadi bendahara umum, berarti mahasiswa mempuyai tanggung mengambil keputusan sendiri tanpa adanya pengaruh dari orang lain.

Keempat, Nilai kedisiplinan dapat diwujudkan antara lain dalam bentuk pembiasaan dalam berperilaku disiplin di Jurusan PPKn Untirta yang telah ditekankan oleh kemampuan mengatur waktu dengan baik, kepatuhan pada seluruh peraturan dan ketentuan yang berlaku di kampus, mengerjakan segala sesuatu dengan tepat waktu, dan mampu fokus pada tanggungjawabnya sebagai mahasiswa.

Kelima, Nilai tanggung jawab dapat diwujudkan antara lain dalam bentuk belajar dengan tertib, lulus pada waktu yang tepat dengan nilai yang baik, dan mengerjakan setiap tugas yang diberikan oleh dosen, serta menjaga amanah dan kepercayaan yang diberikan kepadanya. Misalnya ketika mahasiswa terpilih sebagai pengurus Hima PPKn Untirta maupun pengurus kelas, maka ia mengemban tanggung jawab untuk dapat melaksanakan tugasnya dengan baik. Ketika terpilih menjadi ketua umum,

jawab untuk mengelola keuangan Himpunan dengan baik pula.

\section{KESIMPULAN}

Berdasarkan hasil penelitian dan pembahasan, maka dapat diambil 
kesimpulan bahwa, pendidikan antikorupsi merupakan tindakan untuk mengendalikan dan mengurangi korupsi berupa keseluruhan upaya untuk mendorong generasi mendatang untuk mengembangkan sikap menolak secara tegas terhadap setiap bentuk korupsi. Mentalitas antikorupsi ini akan terwujud jika kita secara sadar membina kemampuan generasi mendatang untuk mampu mengidentifkasi berbagai kelemahan dari sistem nilai yang mereka warisi dan memperbaharui sistem nilai warisan dengan situasi-situasi yang baru. Strategi pembelajaran pendidikan antikorupsi di Untirta adalah dengan mengembangkan silabus dan RPS pada kompetensi yang sesuai dengan mengintegrasikan nilai-nilai antikorupsi yang akan ditanamkan pada mahasiswa, misalnya kejujuran, kepedulian, kemandirian, kedisiplinan,

\section{DAFTAR PUSTAKA}

Chazawi, A. (2016). Hukum Pidana Korupsi di Indonesia. Depok: Rajawali Pers.

Herman Suparno, (2008) Pendidikan, Kemanusiaan, dan Peradaban

Indonesia Corruption Watch. (2020). Laporan Pemantauan Tren Pendidikan Kasus Korupsi dan tanggung jawab, integrasi dalam kegiatan pengembangan diri seperti contoh, melakukan pembiasaan dan pembudayaan, pengkondisian, serta kegiatan rutin, kajian rutin, dan keteladan. Selain itu, integrasi dalam kegiatan pengembangan diri, menggunakan pariatif model pembelajaran yang diterapkan di PPKn Untirta. Substansi dari bentuk-bentuk peningkatan moralitas mahasiswa haruslah beranjak dari pembelajaran pendidikan antikroupsi secara maksimal agar nilainilai anti korupsi yang harus diterapkan dalam diri mahasiswa sebagai hasil dari adanya kebijakan pendidikan anti korupsi. Nilai- nilai anti korupsi ini meliputi kejujuran, kepedulian, kemandirian, kedisiplinan, dan tanggung jawab. Nilai-nilai inilah yang akan mendukung prinsip-prinsip anti korupsi untuk dapat dijalankan dengan baik.

$$
\begin{array}{ll}
\text { dalam Landasan dan Arah } \\
\text { Pendidikan Nasional Kita, } \\
\text { Soedijarto. Kompas;Jakarta. }
\end{array}
$$

Juwono Sudarsono, (2008)Pendidikan, Kemanusiaan, dan Peradaban dalam Landasan dan Arah Pendidikan Nasional Kita, Soedijarto. Kompas;Jakarta Semester I 2020. Indonesia Corruption Watch.

J. Moleong, Lexy. (2014). Metode Penelitian Kualitatif Edisi Revisi. 
Bandung: PT Remaja Rosdakarya.

Nanang, dkk. (2011). Pendidikan Antikorupsi untuk Perguruan Tinggi. Jakarta: Kemendikbud.

Peraturan Menteri Riset, Teknologi dan Sugiyono. (2017). Metode Penelitian: Pendekatan Kualitatif, Kuantitatif, dan R\&D. Bandung: Alfabeta.

\section{Pendidikan}

Ting

gi (Permenristekdikti) No. 33 Tahun 2019.
Wibowo, Agus. 2014. Pendidikan Anti Korupsi di Sekolah. Yogyakarta. Pustaka Pelajar. 